\title{
Differential protective effects of bisphosphonates and denosumab on primary breast cancer risk, potentially to be modified by statins: a retrospective study using electronic health records
}

\section{Alexander Stanoyevitch}

California State University - Dominguez Hills, department of mathematics

Lei Zhang ( $\square$ lei_248@hotmail.com )

https://orcid.org/0000-0002-0422-6862

Javier Sanz

University of California at Los Angeles, clinical and Translational Science Institute

Robert Follett

University of California at Los Angeles, Clinical and Translational Science Institute

Douglas Bell

University of California at Los Angeles, Clinical and Translational Science Institute

\section{Research article}

Keywords: primary breast cancer risk, statins, bisphosphonates, denosumab

Posted Date: February 17th, 2020

DOI: https://doi.org/10.21203/rs.2.17503/v2

License: (c) (1) This work is licensed under a Creative Commons Attribution 4.0 International License.

Read Full License 


\section{Abstract}

Background: The risks of osteoporosis and breast cancer are increasing in elderly women, as well as hyperlipidemia. Bisphosphonates and denosumab are recommended for treatment of osteoporosis, and statins are used for hyperlipidemia. There are different and overlapping pharmacodynamics among bisphosphonates, denosumab and statins. We aim to assess effects of bisphosphonates and denosumab on breast cancer, possibly affected by statins use.

Methods: This retrospective cohort is consisted of 97,671 women elder than 50 years with no previous history of malignancy and no cancer other than breast during follow-up, including 778, 2326, 15287 and 7631denosumab, bisphosphonates, statins and hormone for postmenopausal symptoms ever users. Univariate and bivariate analysis, and the Cox Proportional Hazards multi-variate model are performed.

Results: Over an average of 3.6 years follow up, the breast cancer risks counted after 365 days of latency are $1.54 \%$ (12/778) for denosumab, $0.52 \%$ (12/2326) for bisphosphonates, compared to $0.65 \%$ (99/15287) in statins ever use group, 0.26\% (20/7631) in hormone users for menopausal symptoms and $1.38 \%(1032 / 74867)$ in control group. The significant difference of breast cancer risk between denosumab and bisphosphonates group $(p=0.0047)$ is supported by the Log-rank test $(p=0.0004)$. The multivariate model is in partial agreement with the uni- and bivariate analysis. Further subgroup analysis revealed that concurrent use of statins in denosumab prescribers lowered the breast cancer risk to $0.89 \%$ (2/224), but with no significantly change of breast cancer risk in bisphosphonates group $(7 / 919,0.762 \%)$.

Conclusion : Our data suggest superior protective effects of bisphosphonates over denosumab on breast cancer risk in elderly women. Statins could potentially exert breast cancer protective effect in denosumab users with no synergistic effect in patients taking bisphosphonates. A large scale study with long term follow up is needed.

\section{Background}

Both osteoporotic fracture and cancer can be a devastating personal and social economic burden, and the risks for both are increasing when the modern life expectancy is growing over 80 years old. Seventyone percent of osteoporotic fractures occur in women, while breast cancer is the most common tumor all over the world [1-3]. The effects of anti-osteoporosis medication on breast cancer are a debate and a concern.

Currently, bisphosphonates (Alendronate, risedronate, zoledronic acid) and denosumab (a RNAKL inhibiting antibody) are recommended by USPSTF to treat osteoporosis in postmenopausal women younger or older than 65 years (USPSTF) [2].

Bisphosphonates and denosumab are both anti-resorption drugs inhibiting the osteoclasts activity, but with different binding sites in the bone. Bisphosphonates bind to bone mineral matrix hydroxyapatite at the surface of bone and especially within the resorption lacunae, occupying the site of resorption 
performed by activated osteoclasts where they could be internalized by the active osteoclasts and inhibit the intracellular mevalonate pathway, leading to impaired function and apoptosis of osteoclasts. Denosumab is a newer monoclonal antibody first approved by FDA for treatment of postmenopausal osteoporosis in June 2010. It suppresses bone resorption by binding to receptor activator of nuclear factor kappa-B ligand (RANKL), preventing it from binding to its receptor on cell surfaces of not only osteoclasts but also osteoclasts precursors and decreasing osteoclast formation, activity, and survival $[4,5]$.

The anti-osteoporotic effects of bisphosphonates and denosumab are different: denosumab is more effective and faster in improving bone mass density; but effects of bisphosphonates continue for years after drug discontinuation because they are imbedded in the bone while denosumab discontinuation fully and rapidly reverse its effects on bone markers and bone mineral density [4-6]. Denosumab is contraindicated in severe infection, but is preferred in patients with renal failure.

Although they both are well-established therapeutic options to prevent metastatic bone disease and adjuvant therapy-induced bone loss in breast cancer [7], different cancer modification effects are proposed by preclinical studies.

The pharmaceutical effects of bisphosphonates are mediated by estrogen related receptor a (ERRa) [810]. ERRa plays roles in osteoporosis and breast cancer development. ERRa transcriptional activity is enhanced by cholesterol and suppressed by statins and bisphosphonates [11-12]. Meanwhile, the epigenetic impacts of statin and bisphosphonates on DNA methylation, histone deacetylation and microRNAs occurring in normal cells could be both cancer preventing and promoting [13]. RANKL/RANK/OPG system (receptor activator of nuclear factor/RANK ligand/ osteoprotegerin) is not only critical for the regulation of osteoclast differentiation/activation and calcium release from the skeleton, but also can be regarded as a major downstream mediator of progesterone-driven mammary epithelial cells proliferation, potentially contributing to breast cancer initiation and progression [14]. The entangled and far-reached regulatory network is summarized in Figure 1

Epidemiological studies have shown that bisphosphonates have variable non-adverse, e.g. protective or no related risk towards female breast cancer [15-24], although some reports showed that alendronate may be associated with higher risks in lung and liver cancers $[25,26]$. A recent study suggests a potential protective effect of denosumab ever use on breast cancer risk in a cohort of older women previously treated with bisphosphonates [27]. It is not clear whether this protective effect is due to lingering effects of previous bisphosphonates use. Initial epidemiological study based on the Nurses' Health Study (NHS) cohort did not show protective effects of statins on breast cancer, when anti-osteoporosis therapy was not considered in either medication or control groups [28].

The osteoporosis risk increases after menopause, which is on average by age of 51 , and this is also the early starting age anti-osteoporosis medications are provided. We set the start of our observation time as age 50 and elder. 
PURPOSE: We aim to examine and compare any protective effects against primary breast cancer of the two most widely-used anti-osteoporosis medications: denosumab and bisphosphonates, and explore their relationship with antihyperlipidemic drug statins in females 50 years of age or older.

\section{Methods}

Population:

This study was approved by the Research Ethics Board of University of California at Los Angeles (UCLA). Inclusion criterions: female, age 50 or older at their first visit, with at least two ambulatory encounters in one year. Exclusion criterions: previous diagnosis of cancer in the first encounter and cancer diagnosis other than breast cancer during follow-up.

Data retrieval:

A 3.6-year duration of chronological clinical information were extracted from the Clarity data base which has been daily transferred from the Epic application (Chronicles). The requested data output for this project are in nine CSV (comma-separated values) format files including parameters of ICD, SNOMED diagnoses, labs, medications, family history, allergies, vital signs and demographic information. The medications include prescriptions linked to pharmacy fill-up or in-house administration. All HIPAA (Health Insurance Portability and Accountability Act) identifiers have been stripped from the data sets. These data sets were linked using unique encoded identifiers.

Analytics:

Study_groups:

In addition to denosumab and bisphosphonates, we also examined possible interactions with two other popular drug classes: hormones and statins. The patients were separated into two mutually exclusive groups:

Medication group includes: 1) denosumab, 2) bisphosphonates (Alendronate, Risedronate, Zoledronic, Pamidronate, Ibandronate), 3) statins (Simvastatin, Atorvastatin, Rosuvastatin, Fluvastatin, Pitavastatin, Lovastatin, Pravastatin), 4) hormones (used by women to reduce menopausal symptoms including patch, tablets or vaginal ring of estradiol, estrogen, Norethindrone Acetate-Ethinyl Estradiol).

Control group definition is: hospital visitors who have never been prescribed bisphosphonates, denosumab, statins or hormones.

Breast cancer identification: ICD-9 (V10.3) and ICD-10 (Z85.3) codes which are authoritative tools for disease identification, besides their association with claims and reimbursement are used to identify breast cancer patients. Breast cancer patients definitions are: 1) patients who were diagnosed with breast cancer 365 days or later after they were first prescribed any of these four medication groups; 2) patients 
in the control group who were diagnosed with breast cancer at least 365 days after the first encounter. Exclusion criterions are:

Of note, to focus on primary breast cancer study, and to exclude situations when denosumab/bisphosphonates are used to treat bone metastatic tumor or myeloma, the followings are applied: 1) excluding patients who have previous history of malignancy in first encounter; 2) breast cancer cases counting started after one year latency in all subgroups; 3) patient exposed to denosumab or bisphosphonates who has cancer diagnoses other than breast type to be excluded from analysis; 4) patients with breast cancer diagnosis before denosumab or bisphosphonates administration excluded.

Covariates We examined controlling our comparisons against the following relevant covariates: body mass index (BMI), blood pressure, hyperlipidemia, diabetes status, breast cancer family history, alcohol ever use. Those parameters are extracted from either ICD-diagnosis codes or laboratory measurements, or encounter documentation.

Statistical analysis:

All data analyses and application of inclusion and exclusion criterions were performed using the $\mathrm{R}$ statistical software package (with R Studio).

The univariate and bivariate analysis include: a Kaplan-Meier plot and its associated log-rank test, relative risks, odds ratios. Confidence intervals, $\mathrm{P}$ values (one or two-tail, significance level: $\mathrm{P}<0.01$ ) were provided whenever feasible.

For completeness we also include a Cox Proportional Hazards multi-variate model.

The multivariate model includes the four main drugs under study: denosumab, bisphosphonates, statins, and hormones. For each patient in the medication group, we computed the last date any of the four drugs that they took and added that number to 365 to determine the threshold after which a breast cancer diagnoses gets counted.

\section{Results}




\section{Generation of study cohort}

The UCLA health system has around 180 primary and specialty care practices in southern California. There are 285,254 patients who are age 50 or older at their first visit on or after date of 01/01/2012. 205,952 patients who are older than 50 , with at least two ambulatory encounters in one year from $1 / 1 / 2012$ to $7 / 1 / 2016$ in UCLA electronic health system were first sorted out. After excluding male patients and patients who have had previous diagnosis of cancer in first encounter and cancer diagnosis other than breast cancer during follow-up, our final cohort includes 92207 female patients.

\section{Differential breast cancer risk between denosumab and bisphosphonates group}

Excluding the first-year latency, the breast cancer risk in denosumab group is 1.54\% (12/778), compared to $0.52 \%(12 / 2326)$ in bisphosphonates. The accumulative risk is statistically significant $(p=0.0047)$ [Table 1], as well as the breast cancer distribution in follow-up time of 3 years as shown by Kaplan-Meier plot and log-rank test ( $p=0.0004)$ [Figure 2]. Among denosumab and bisphosphonates ever users, only $84(84 / 3020=2.8 \%)$ patients have taken both medications during follow-up. This number is too small to be of any statistical significance.

The comparable co-variates between the two groups are summarized in [Table 2] and [suppl Table 1].

The multivariate model showed a trend of lower breast cancer risk in bisphosphonates group compared to denosumab group [suppl Fig 1]

3. Breast cancer risk stratification demonstrating breast cancer risk in hyperlipidemic patients paradoxically lower in denosumab group $(2 / 181,1.105 \%)$ than in bisphosphonates group (10/526, $1.901 \%)$ [Table 2]

We next examine whether this risk difference between denosumab and bisphosphonates continues to hold in the stratifications of risk factors related to general health and physical activity.

Of note, in the medication groups of denosumab, bisphosphonates, statins and hormones, 3218 women out of 26,022 have taken more than one type of the four medications, accounting for $3 \%$ $(3218 / 97671)$ of the cohort population. The control group are hospital visitors $(n=74867)$ who have never been prescribed bisphosphonates, denosumab, statins or hormones.

Our data analyses showed that denosumab and control groups have similar breast cancer risk (1.54\% versus $1.38 \%, \mathrm{P}=0.0193)$; the breast cancer risks in bisphosphonates $(0.52 \%)$, statins $(0.65 \%)$ and hormone $(0.26 \%)$ groups are significantly lower than control $(P=0.0008,<0.0004,<0.0004)$. The differences of breast cancer risk hold constant in stratifications of body mass index, blood pressure, diabetes status [Table 2]. In blood lipid level stratification, however, the breast cancer risk is paradoxically lower in denosumab group (1.11\%) compared to that in bisphosphonates group (1.90\%) in hyperlipidemic patients, although the risks in normal lipid group is the opposite (higher in denosumab1.68\%, lower in bisphosphonates $0.44 \%$ ). This has raised a concern that other lipid lowering medications such as statins may confound breast cancer risk in denosumab users.

The hormone group in this cohort is characterized by lowest proportions of hyperlipidemia, diabetes, hypertension, and highest proportion of lean body figure (body mass index less than 25) compared to other groups. This is associated with lowest breast cancer risk among all the groups despite that this group has a higher incidence of breast cancer family history.

Of note, the proportion of hyperlipidemia is low in the control. This is largely due to removal of statin treatment group from the control. Also, only $38 \%$ of patients in statins group have a diagnosis of hyperlipidemia, this is because statins are not only indicated for hyperlipidemia situation, but also recommended to optimize lipid levels in diabetes even if those patients may not qualify for the diagnosis of hyperlipidemia [33].

The numbers of missing data vary among categories. Alcohol ever use category has the highest frequency of missing data (up to $25 \%$ ). Nonetheless, there is no significant difference of missing data among the four medication groups and control group. 
3. Concurrent use of statins seems to further lowering breast cancer risk in the denosumab group but not in the bisphosphonates group

The concurrent statins use is $29 \%(224 / 778)$ in denosumab groups and $40 \%(919 / 2326)$ in bisphosphonates group $(\mathrm{p}<0.001 \%)$. When we looked at the breast cancer risk in concurrent medication users, we found that that concurrent denosumab and statin use lowered the breast cancer risk to $0.89 \%$ $(2 / 224$, p not applicable, because at least one of the samples does not satisfy the requirement that $n p$ and $n(1-p)$ must both be greater than or equal to 5). In contrast, concurrent use of bisphosphonates and statin have a breast cancer risk slightly higher but not statistically significant $(0.76 \%, 7 / 919, p=0.0505)$ [Table 1] [suppl Fig 2].

The number of concurrent hormone user is about 3 times lower than that of concurrent statins user in denosumab groups $(87 / 778=11 \%)$ and bisphosphonates group $(279 / 2326=12 \%)$ (Table 1$)$. This is concordant with the findings that the hormone group in our cohort has the youngest age and has less comorbidity, which may explain lowest breast cancer risk observed.

\section{Discussion}

1. Rationale and flexibility of medication grouping and covariates selections using data from electronic healthy records

Both denosumab and bisphosphonates are approved by FDA to treat bone metastatic solid tumors or hematopoietic tumor myeloma involving bone. Those clinical scenarios are excluded from this study by excluding any patients with malignant diagnosis in first encounter, and any cancer diagnosis other than breast carcinoma during follow-up, and applying at least 365-day waiting time in medication groups for breast cancer case counting (any breast cancer cases diagnosed 365 days before medication or 365 days within first encounter were dropped off from analysis).

Denosumab is administrated subcutaneously every 6 months. Bisphosphonates are administered at variable interval of daily, weekly, quarterly or yearly regime. Because of the lingering effect of bisphosphonates and low-frequency standard administration regime for denosumab, we classify the antiosteoporosis therapy as two category dichotomous binary data, e.g., with or without treatment.

It is natural to ask whether the breast cancer patients in each subgroup have different prognosis. Breast cancer prognosis is currently stratified into 8 groups based on anatomic characters including $T$ (tumor), $\mathrm{N}$ (nodes), M (metastasis), and biological types including estrogen/progesterone receptor, HER2 status according to AJCC $8^{\text {th }}$ edition [34]. Furthermore, categorization based on genome, RNA or protein expression profiles are also applied [34]. Such complex stratifications require large number of breast cancer cases for testing of prognosis difference across each subgroup. This question may be addressed in future large-scale studies. Also bearing in mind, relative proportions of cancer subtypes may neither translate into absolute risks nor reveal the underlying tumor biology. 
Hormone replacement is required for menopausal symptom control in some patients due to decreased endogenous estrogen level. The hormone replacement may indicate both decreased risk for breast cancer (lower endogenous hormone level) and increased risk (supplemental hormone). We therefore separate this group from our control.

Statins ever users have also been separated from control because of afore mentioned signal pathway overlapping with bisphosphonates.

Well-accepted breast cancer risks include family history, increased hormone level, adiposity (body mass index), alcohol ever use [3]. Smoking is not considered a risk factor for breast cancer [3]. Moreover, diabetes status, which has not been mentioned as a risk factor for breast cancer in WHO Classification of Tumors of the Breast, has been reported to be associated with breast cancer [29-31]. We included those in our covariate analysis, besides age which by itself is a cancer risk. We compared parameters of blood pressure and lipidemia which are related to general health and physical activity. The co-variate analysis showed that there is no significant biomedical difference between the denosumab and bisphosphonates ever use groups.

\section{Comparison of our results with other studies}

There are inconsistent results on association of breast cancer risk and bisphosphonates use. Most previous large cohort studies have shown that bisphosphonates have either a protective effect or no adverse effect in primary breast cancer prevention [15-22]. The only randomized control trials showed that 3-4 years of bisphosphonate treatment did not decrease the risk of invasive breast carcinoma in postmenopausal women [23]. However, the randomized control trials were not initially designed to study breast cancer outcome and they might be at high risk of selective reporting bias. Overall, systemic reviews and meta-analyses agreed upon a significantly decreased risk of primary breast cancer in bisphosphonates users[24-26]. This is in accordance with our findings.

Different from bisphosphonates whose cancer association has been studied for a decade, there is only one paper recently published addressing the relationship between denosumab and breast cancer risk. This first case-control study showed that in a cohort of older women previously treated with bisphosphonates, denosumab use was associated with a $13 \%$ decreased breast cancer risk (HR $=0.87$; $95 \% \mathrm{Cl} 0.76-1.00$ ) [27]. There was no relationship between increasing number of denosumab doses and breast cancer risk (P-trend $=0.15)$ [27]. Our cohort study, which has a similar length of follow-up to the former study but with a bisphosphonates and denosumab co-medication rate of $2.8 \%(84 / 3020=2.8 \%)$, did not come to the same conclusion. We showed that breast cancer risk in denosumab users is not significantly different from the control, although our study demonstrated breast cancer lowering effect of bisphosphonates.

The initial epidemiological study on statins and breast cancer association is from the Nurses' Health Study (NHS) cohort [28]. It showed no associated risk of breast invasive carcinoma in statins users, but the co-medication analysis did not include bisphosphonates use. All the cohort and case control studies 
which focused on the relationship of bisphosphonates and breast cancer did not separate statins use from control group either [15-23]. In our study, statins showed similar breast cancer protective effect as bisphosphonates in consistence with published preclinical research [11-13]. It is possible that the comparable breast cancer protective effect of bisphosphonates or statins might be masked when the control group has co-medication of either of these two drugs.

We also showed that co-medication of denosumab and statins led to lower cancer risk compared to denosumab ever use, although the statistical significance is not applicable due to events (cancer cases) less than 5. Plans are underway for our acquiring even larger medical records data sets to further investigate such concepts.

This healthier biomedical status in the hormone group may explain the lowest breast cancer risk among all the groups despite this group has a higher incidence of breast cancer family history. The absence of increased breast cancer risk may also be related to low dose and formulation of hormone in this group of patients. There is a great discrepancy on breast cancer risk and postmenopausal hormone use [3].

In a contemporary observational cohort study, more than 100,000 women ages 50 to 71 were followed prospectively for 15 years. It showed that long-term hormonal contraceptive use reduced ovarian and endometrial cancer risks by $40 \%$ and $34 \%$, respectively, with no increase in breast cancer risk regardless of family history [32].

\section{Limitation}

The electronic health system records individualized personal care, in compliance with standard patient care. It enables us to analyze potential drug interaction among anti-osteoporosis drugs, statins and exogenous hormones in the real world. Our study also has limitations. Age at menarche, breastfeeding history are missing in majority of our electronic health records.

The multi-variate model turned out to be in partial agreement with our univariate and bivariate analysis conclusions, but the main drawback of a multivariate survival analysis here stems from how we counted breast cancer cases within the groups. The multivariate model includes the four main drugs under study: denosumab, bisphosphonates, statins, and hormones. For each patient in the medication group, we needed to compute the last date that any of the four drugs that they took was prescribed and add that number to 365 to determine the threshold after which a breast cancer diagnoses gets counted. This removes that uniformity that we had maintained in the univariate and bivariate analysis.

\section{Conclusion}

This is the first study to compare the risk of primary breast cancer between bisphosphonates and denosumab users head-to-head. The results may provide information for clinical decision when breast cancer is a concern and patients are treated for osteoporosis with or without comorbidity of hyperlipidemia. 
Our data suggest superior protective effects of bisphosphonates over denosumab on breast cancer risk in elderly women. Statins could potentially exert breast cancer protective effect in denosumab users but no synergistic effect in patients taking bisphosphonates.

\section{Declarations}

\section{Authors' contributions:}

Data analysis - AS and LZ; data extraction - JS and RF; study design - LZ and DB; manuscript preparation - LZ and AS; DB oversees the project.

\section{Acknowledgement:}

We thank Marianne Zachariah from CTSI, University of California at Los Angeles for consulting

\section{Funding}

This research was partially supported by NIH National Center for Advancing Translational Science (NCATS) UCLA CTSI Grant Number UL1TR001881.

\section{Availability of Data and Materials}

The data of this study are available from the Clinical and Translational Science Institute, UCLA. HIPPA restrictions apply.

\section{Ethics declarations}

This study was approved by the Research Ethics Board of University of California at Los Angeles

\section{Consent for publication}

Not applicable

\section{Competing interests}

The authors declare that they have no competing interests.

\section{Abbreviations}

RANKL: Receptor Activator Of Nuclear Factor Kappa-B Ligand

ERRa: Estrogen Related Receptor a

DNA: Desoxyribonucleic Acid 
RANK: Receptor Activator Of Nuclear Factor-kB

RANKL: RANK ligand

OPG: Osteoprotegerin

NHS: Nurses' Health Study

FDA: Food and Drug Administration

UCLA: University of California at Los Angeles

CSV: Comma-Separated Values

ICD: International Classification of Diseases

SNOMED: Systematized Nomenclature of Human Medicine

HIPPA: Health Insurance Portability and Accountability Act

BMl: Body Mass Index

WHO: World Health Organization

AJCC: American Joint Committee on Cancer

HER2: Human Epidermal Growth Factor Receptor 2

TNM: Tumor Nodes Metastasis

RNA: Ribonucleic Acid

95\% Cl: 95\% confidence interval

\section{References}

1. Qaseem A, Forciea MA, McLean RM, et al. Treatment of low bone density or osteoporosis to prevent fractures in men and women: a clinical practice guideline update from the American College of Physicians. Ann Intern Med. 2017;166:818-839

2. US Preventive Services Tasj Forces, Curry SJ, Krist AH, Owens DK, et al. Screening for osteoporosis to prevent fractures: US preventive services task force recommendation statement. JAMA. 2018; 319(24):2521-2531

3. Lakhani S. R., Ellis I. O., Schnitt S. J., tan P.H., van de Vijver M. J. (Eds): WHO Classification of Tumors of the Breast. IARC:Lyon : p14-17, 2012 
4. Anastasilakis AD, Polyzos SA, Makras P. Therapy of endocrine disease: denosumab vs. bisphosphonates for the treatment of postmenopausal osteoporosis. Eur J Endocrinol. 2018; 179(1):R31-R45

5. Kim SY, Ok HG, Birkenmaier C et al. Can denosumab be a substitute, competitor, or complement to bisphosphonates? Korean J Pain. 2017; 30(2):86-92

6. Lyu H, Jundi B, Xu C et al. Comparison of denosumab and bisphosphonates in patients with osteoporosis: a meta-analysis of randomized controlled trials. J Clin Endocrinol Metab. 2019; 104(5): 1753-1765

7. Tesfamariam Y, Jakob T, Wockel A, et al. Adjuvant bisphosphonates or RANK-ligand inhibitors for patients with breast cancer and bone metastases: a systematic review and network meta-analysis. Crit Rev Oncol Hematol. 2019; 137:1-8

8. Khosla S, Oursler MJ, Monroe DG, Estrogen and the skeleton. Trends Endocrinol Metab. 2012; 23(11):576-81

9. Carroll JS, Meyer CA, Song J, et al. Genome-wide analysis of estrogen receptor binding sites. Nat Genet: 38(11). 2006;1289-97

10. Qin L, Liu Y, Wang Y et al. Computational characterization of osteoporosis associated SNPs and Genes identified by Genome-wide association studies. PLoS One. 2016; 11(3): e0150070

11. Wei W, Schwaid AG, Wang X et al. Ligand activation of ERRa by cholesterol mediates statin and bisphosphonates effects. Cell Metab. 2016; 23(3):479-91

12. Casaburi I, Chimento A, De Luca A et al. Cholesterol as an endogenous ERRa agonist: a new perspective to cancer treatment. Front Endocrinol (Lausanne). 2018; 9:525, eCollection

13. Karlic $\mathrm{H}$, Thaler $\mathrm{R}$, Gerner $\mathrm{C}$ et al. Inhibition of the mevalonate pathway affects epigenetic regulation in cancer cells. Cancer Genet. 2015; 208(5):241-252

14. Infante M, Fabi A, Cognetti F, et al. RANKL/RANK/OPG system beyond bone remodeling: involvement in breast cancer and clinical perspectives. J Exp Clin Cancer Res. 2019; 38(1): 12

15. Vinogradova Y, Coupland C, Hippisley-Cox J. Exposure to bisphosphonates and risk of common nongastrointestinal cancers: series of nested case-control studies using two primary-care databases. $\mathrm{Br}$ J Cancer. 2013; 109(3):795-806

16. Rennert G, Pinchev M, Rennert HS. Use of bisphosphonates and risk of postmenopausal breast cancer. J Clin Oncol. 2010; 28(22): 3577-3581 
17. Newcomb PA, Trentham-Dietz A, Hampton JM. Bisphosphonates for osteoporosis treatment are associated with reduced breast cancer risk. $\mathrm{Br} \mathrm{J}$ Cancer. 2010; 102(5):799-802

18. Vestergaard P, Fischer L, Mele M, Mosekilde L, Christiansen P. Use of bisphosphonates and risk of breast cancer. Calcif Tissue Int. 2011; 88(4):255-262

19. Fournier A, Mesrine S, Gelot A, et al. Use of bisphosphonates and risk of breast cancer in a French cohort of postmenopausal women. J Clin Oncol. 2017; 35(28):3230-3239

20. Cardwell CR, Abnet CC, Veal P, et al. Exposure to oral bisphosphonates and risk of cancer. Int J Cancer. 2012; 131(5):E717-E725

21. Chlebowski RT, Chen Z, Cauley JA, et al. Oral bisphosphonate use and breast cancer incidence in postmenopausal women. J Clin Oncol. 2010; 28(22):3582-3590

22. Chiang $\mathrm{CH}$, Huang $\mathrm{CC}$, ChanWL, et al. Oral alendronate use and risk of cancer in postmenopausal women with osteoporosis: a nationwide study. J Bone Miner Res. 2012; 27(9):1951-1958

23. Hue TF, Cummings SR, Cauley JA, et al. Effect of bisphosphonate use on risk of postmenopausal breast cancer: results from the randomized clinical trials of alendronate and zoledronic Acid. JAMA Intern Med. 2014; 174(10):1550-1557

24. Liu Y, Zhang $X$, Sun $H$, et al. Bisphosphonates and primary breast cancer risk: an updated systematic review and meta-analysis involving 963,995 women. Clin Epidemiol. 2019; 11:593-603

25. Chen L-X, Ning G-Z, Zhou Z-R, et al. The Carcinogenicity of Alendronate in Patients with Osteoporosis: Evidence from Cohort Studies. PLoS ONE. 2015; 10(4): e0123080

26. LeeWY,SunLM,LinMC, et al. A higherdosage of oral alendronate will increase the subsequent cancer risk of osteoporosis patients in Taiwan: a population-based cohort study PloS ONE. 2012; 7(12):e53032

27. Giannakeas V, Cadarette SM, Ban JK et al. Denosumab and breast cancer risk in postmenopausal women: a population-based cohort study. Br J Cancer. 2018; 119(11):1421-1427

28. Borgquist S, Tamimi RM, Chen WY et al. Statin use and breast cancer risk in the nurses' health study. Cancer Epidemiol Biomarkers Prev. 2016; 25(1): 201-6

29. Larsson SC, Mantzoros CS, Wolk A. Diabetes mellitus and risk of breast cancer: a meta-analysis. Int J Cancer. 2007; 121(4):856-862

30. Hardefeldt PJ, Edirimanne S, Eslick GD. Diabetes increases the risk of breast cancer: a meta-analysis. Endocr Relat Cancer. 2012; 19(6): 793-803 
31. Neuhouser ML, Aragaki AK, Prentice RL, et al. Overweight, obesity, and postmenopausal invasive breast cancer risk. JAMA Oncol. 2015; 1(5):611-621

32. Michels KA, Pfeiffer RM, Brinton LA, Trabert B. Modification of the associations between duration of oral contraceptive use and ovarian, endometrial, breast, and colorectal cancers. JAMA Oncol. 2018; $4(4): 516-521$

33. Eldor R, Raz I. American diabetes association indications for statins in diabetes: is there evidence? Diabetes Care. 2009; 32(suppl 2): S384-S391

34. Updated breast chapter of the AJCC cancer staging manual. https://cancerstaging.org/About/news/Pages/UpdatedBreast-Chapter-for-8th-Edition.aspx

\section{Tables}

Table 1. Comparison of breast cancer risks among different medication groups

\begin{tabular}{|c|c|c|c|c|}
\hline & $\begin{array}{l}\text { Breast } \\
\text { cancer risk }\end{array}$ & $\begin{array}{l}95 \% \\
\text { CI }\end{array}$ & $\begin{array}{l}\mathrm{P} \text { (group risk }< \\
\text { control risk) }\end{array}$ & $\begin{array}{l}\mathrm{P} \text { (cancer risk } \\
\text { of denosumab } \neq \text { bisphosphonates) }\end{array}$ \\
\hline \multicolumn{5}{|l|}{ Single medication ever use } \\
\hline denosumab & $\begin{array}{l}1.54 \% \\
(12 / 778)\end{array}$ & $\begin{array}{l}0.68 \%, \\
2.41 \%\end{array}$ & 0.0193 & \multirow[t]{2}{*}{0.0047} \\
\hline bisphosphonates & $\begin{array}{l}0.52 \% \\
(12 / 2326)\end{array}$ & $\begin{array}{l}0.22 \%, \\
0.81 \%\end{array}$ & 0.0008 & \\
\hline statins & $\begin{array}{l}0.65 \% \\
(99 / 15287)\end{array}$ & $\begin{array}{l}0.52 \%, \\
0.78 \%\end{array}$ & $<0.0004$ & \\
\hline $\begin{array}{c}\text { Hormone (for } \\
\text { postmenopausal symptoms) }\end{array}$ & $\begin{array}{l}0.26 \% \\
(20 / 7631)\end{array}$ & $\begin{array}{l}0.15 \%, \\
0.38 \%\end{array}$ & $<0.0004$ & \\
\hline \multicolumn{5}{|l|}{ Co-medication ever use } \\
\hline Denosumab+statins & $0.89 \%(2 / 224)$ & $\begin{array}{l}0.24 \%, \\
3.90 \%\end{array}$ & NA & \multirow[t]{2}{*}{ NA } \\
\hline Bisphosphonates+statins & $0.76 \%(7 / 919)$ & $\begin{array}{l}0.37 \%, \\
1.56 \%\end{array}$ & 0.0505 & \\
\hline Denosumab+hormone* & $0 \%(0 / 87)$ & $\begin{array}{l}0, \\
4.23 \%\end{array}$ & NA & \multirow[t]{2}{*}{ NA } \\
\hline Bisphosphonates+hormone* & $0 \%(0 / 279)$ & $\begin{array}{l}0, \\
1.36 \%\end{array}$ & NA & \\
\hline Control & $\begin{array}{l}1.38 \% \\
(1032 / 74867)\end{array}$ & & & \\
\hline
\end{tabular}

NA: not applicable, because at least one of the samples does not satisfy the requirement that $\mathrm{np}$ and $\mathrm{n}(1-\mathrm{p})$ must both be greater than or equal to 5

Hormone*: hormone medication for postmenopausal symptoms 
Table 2. Patient characters and stratified breast cancer risk in different medication groups 


\begin{tabular}{|c|c|c|c|c|c|}
\hline & $\begin{array}{l}\text { Denosumab } \\
\mathrm{N}=778\end{array}$ & $\begin{array}{l}\text { Bisphosphonates } \\
\text { N=2326 }\end{array}$ & $\begin{array}{l}\text { Statins } \\
N=15287\end{array}$ & $\begin{array}{l}\text { Hormone } \\
N=7631\end{array}$ & $\begin{array}{l}\text { control } \\
\mathrm{N}=74867\end{array}$ \\
\hline $\begin{array}{l}\text { If first encounter } \\
\text { arter, median, mean, 3rd } \\
\text { ) }\end{array}$ & $\begin{array}{l}62,68, \\
69.47,78\end{array}$ & $\begin{array}{l}61,67,68.59 \\
76\end{array}$ & $\begin{array}{l}60,67 \\
68.23,75\end{array}$ & $\begin{array}{l}55,60 \\
61.9,67\end{array}$ & $\begin{array}{l}56,63 \\
64.47,71\end{array}$ \\
\hline $\begin{array}{l}\text { ly history of breast } \\
\text { r }(\%, n=)\end{array}$ & $15 \%(119)$ & $12 \%(273)$ & $9 \%(1441)$ & $\begin{array}{l}14 \% \\
(1052)\end{array}$ & $\begin{array}{l}7 \% \\
(5187)\end{array}$ \\
\hline \multicolumn{6}{|l|}{ ol ever use $(\%, n=)$} \\
\hline Yes & $33 \%(254)$ & $29 \%(666)$ & $\begin{array}{l}31 \% \\
(4708)\end{array}$ & $\begin{array}{l}45 \% \\
(3446)\end{array}$ & $\begin{array}{l}29 \% \\
(21815)\end{array}$ \\
\hline No & $46 \%(356)$ & $48 \%(1128)$ & $\begin{array}{l}44 \% \\
(6659)\end{array}$ & $\begin{array}{l}31 \% \\
(2372)\end{array}$ & $\begin{array}{l}33 \% \\
(24469)\end{array}$ \\
\hline $\begin{array}{l}\text { Not asked or } \\
\text { ng data }\end{array}$ & $21 \%(168)$ & $23 \%(532)$ & $\begin{array}{l}25 \% \\
(3920)\end{array}$ & $\begin{array}{l}24 \% \\
(1813)\end{array}$ & $\begin{array}{l}38 \% \\
(28583)\end{array}$ \\
\hline \multicolumn{6}{|l|}{ mass index } \\
\hline Mean & 24.99 & 24.91 & 27.88 & 25.15 & 26.54 \\
\hline$>30$ & $15 \%$ & $14 \%$ & $14 \%$ & $15 \%$ & $24 \%$ \\
\hline $\begin{array}{ll} & \text { Breast } \\
\text { r risk } & \\
\end{array}$ & $1.00 \%$ & $0.00 \%$ & $0.68 \%$ & $0.33 \%$ & $2.34 \%$ \\
\hline$<25$ & $51 \%$ & $59 \%$ & $36 \%$ & $57 \%$ & $47 \%$ \\
\hline $\begin{array}{ll}\text { r risk } & \text { Breast } \\
\end{array}$ & $1.50 \%$ & $1.13 \%$ & $0.71 \%$ & $0.20 \%$ & $2.35 \%$ \\
\hline elative risk $(95 \% \mathrm{CI})$ & $\begin{array}{l}0.64(0.28, \\
1.44)\end{array}$ & $0.49(0.27,0.85)$ & $\begin{array}{l}0.30 \\
(0.21 \\
0.44)\end{array}$ & $\begin{array}{l}0.09 \\
(0.04 \\
0.19)\end{array}$ & 1.00 \\
\hline \multicolumn{6}{|l|}{ pressure(BP) } \\
\hline $\begin{array}{l}\text { Mean } \\
\text { slic/diastolic) }\end{array}$ & $127 / 73$ & $128 / 72$ & $130 / 73$ & $125 / 73$ & $128 / 74$ \\
\hline ertension $(>140 />90)$ & $26 \%$ & $29 \%$ & $33 \%$ & $21 \%$ & $31 \%$ \\
\hline $\begin{array}{ll}\text { r risk } & \text { Breast } \\
\end{array}$ & $2.87 \%$ & $0.97 \%$ & $0.84 \%$ & $0.47 \%$ & $2.87 \%$ \\
\hline$\overline{\operatorname{Normal}(<120 /<80)}$ & $42 \%$ & $42 \%$ & $36 \%$ & $51 \%$ & $43 \%$ \\
\hline $\begin{array}{ll}\text { r risk } & \text { Breast } \\
\end{array}$ & $1.92 \%$ & $0.93 \%$ & $0.77 \%$ & $0.27 \%$ & $1.83 \%$ \\
\hline Relative risk $(95 \%$ & $\begin{array}{l}1.05(0.47 \\
2.38)\end{array}$ & $0.51(0.24,1.08)$ & $\begin{array}{l}0.42(0.29, \\
0.61)\end{array}$ & $\begin{array}{l}0.15(0.07, \\
0.29)\end{array}$ & 1.00 \\
\hline \multicolumn{6}{|l|}{ tes } \\
\hline Diabetes diagnosis & $10 \%$ & $9 \%$ & $15 \%$ & $6 \%$ & $15 \%$ \\
\hline $\begin{array}{ll}\text { r risk } & \text { Breast } \\
\end{array}$ & $23 \%$ & $23 \%$ & $38 \%$ & $18 \%$ & $15 \%$ \\
\hline $\begin{array}{l}\text { No-diabetic } \\
\text { losis }\end{array}$ & $1.92 \%$ & $0 \%$ & $0.92 \%$ & $0.47 \%$ & $1.35 \%$ \\
\hline r risk $\quad$ Breast & $1.57 \%$ & $1 \%$ & $0.60 \%$ & $0.25 \%$ & $1.38 \%$ \\
\hline Relative risk (95\% & $\begin{array}{l}1.14(0.62, \\
2.07)\end{array}$ & $0.62(0.39,0.99)$ & $\begin{array}{l}0.44(0.35, \\
0.55)\end{array}$ & $\begin{array}{l}0.18 \\
(0.11 \\
0.29)\end{array}$ & 1.00 \\
\hline
\end{tabular}




\begin{tabular}{l|l|l|l|l|l|} 
panel & & & & \\
$\begin{array}{l}\text { Hyperlipidemia } \\
\text { nented (\%) }\end{array}$ & $23 \%$ & $23 \%$ & $38 \% * *$ & $18 \%$ & $5 \% *$ \\
\hline $\begin{array}{l}\text { Br risk } \\
\begin{array}{l}\text { No } \\
\text { lipidemia } \\
\text { nented }\end{array}\end{array}$ & $1.11 \%$ & $1.90 \%$ & $0.90 \%$ & $0.22 \%$ & $2.51 \%$ \\
\hline breast risk & $1.68 \%$ & $0.44 \%$ & & & \\
\hline Relative risk $(95 \%$ & $\begin{array}{l}1.27(0.68, \\
2.38)\end{array}$ & $0.34(0.17,0.68)$ & $\begin{array}{l}0.37(0.17, \\
0.68)\end{array}$ & $\begin{array}{l}0.21(0.13, \\
0.33)\end{array}$ & 1.000 \\
\hline
\end{tabular}

Note: Relative risks are in relation to normal control

* The low number is largely due to removal of statin treatment group from the control.

** Statins are not only indicated for hyperlipidemia situation, but also recommended to optimize lipid levels in diabetes even if those patients may not qualify for the diagnosis of hyperlipidemia [33].

Table 3. co-medications and breast cancer risk in denosumab and bisphosphonates group

\begin{tabular}{|c|l|l|l|}
\hline & Denosumab & Bisphosphonates & $\mathrm{P}$ \\
\hline Statins co-medication & & & \\
\hline Proportion & $29 \%(224 / 778)$ & $40 \%(919 / 2326)$ & $<0.001 \%$ \\
\hline Breast cancer risk & $0.893 \%(2 / 224)$ & $0.762 \%(7 / 919)$ & $\mathrm{NA}^{*}$ \\
\hline Hormone co-medication & & & \\
\hline Proportion & $11 \%(87 / 778)$ & $12 \%(279 / 2326)$ & 0.2041 \\
\hline Breast cancer risk & $0 \%(0 / 87)$ & $0 \%(0 / 279)$ & $\mathrm{NA}^{*}$ \\
\hline
\end{tabular}

* The significance level $(P)$ is not applicable because cancer case number is $<5$

\section{Figures}


Figure 1. Proposed regulatory network of denosumab, statins and bisphosphonates in breast cancer

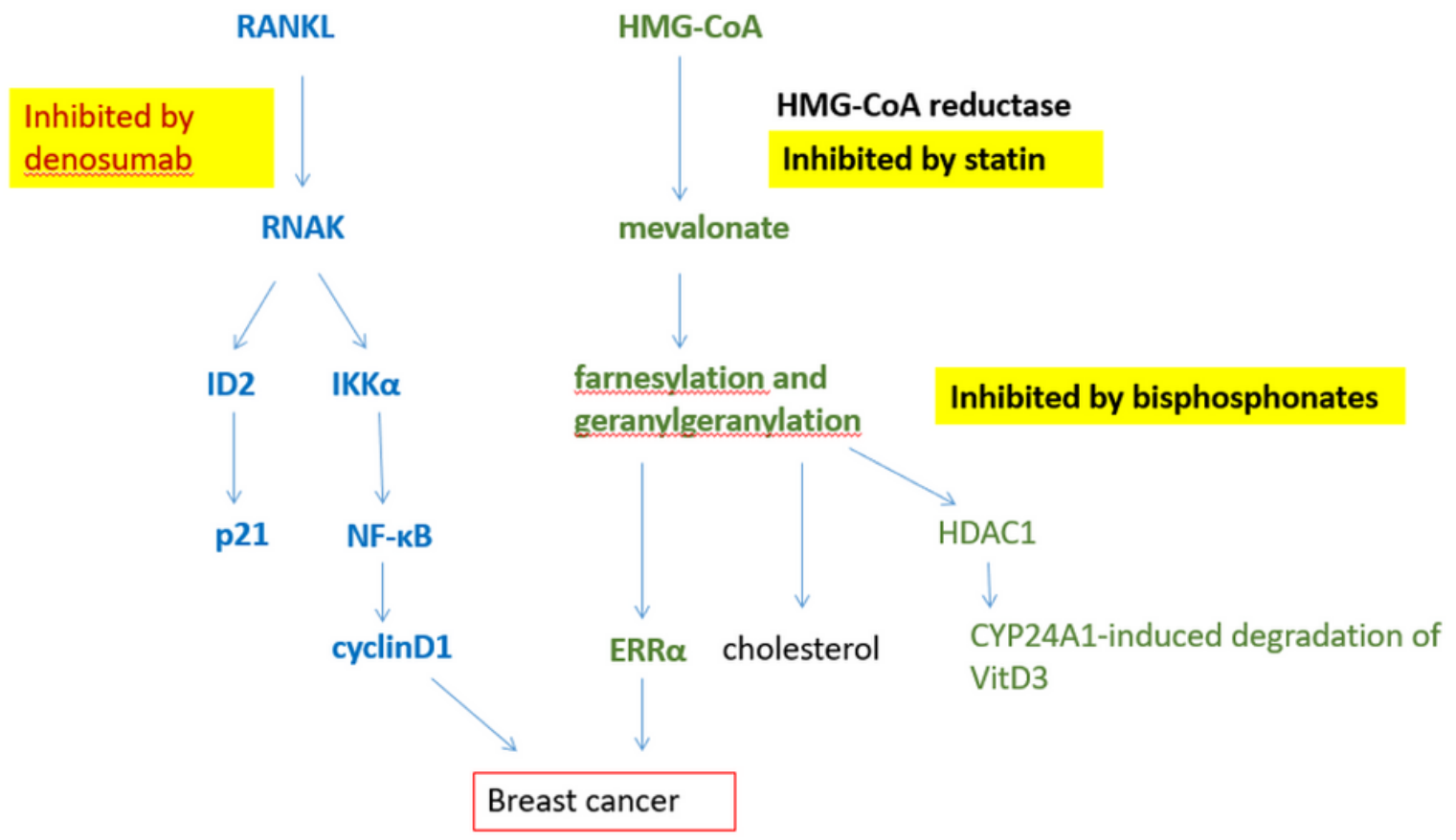

Figure 1

Proposed regulatory network of denosumab, statins and bisphosphonates in breast cancer

Figure 2. Cumulative breast cancer free diagnosis in bisphosphonates and denosumab users, Kaplan-Meier plot and log-rank test

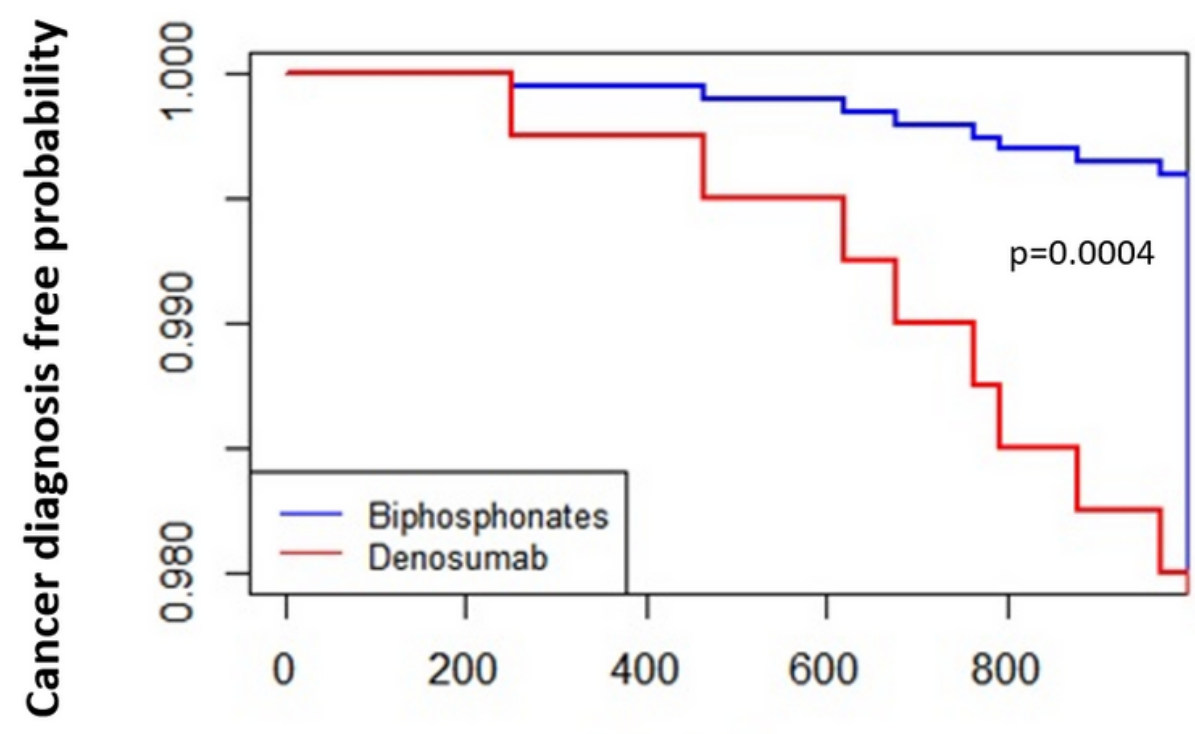

Time in Days 
Figure 2

Cumulative breast cancer free diagnosis in bisphosphonates and denosumab users, Kaplan-Meier plot and log-rank test

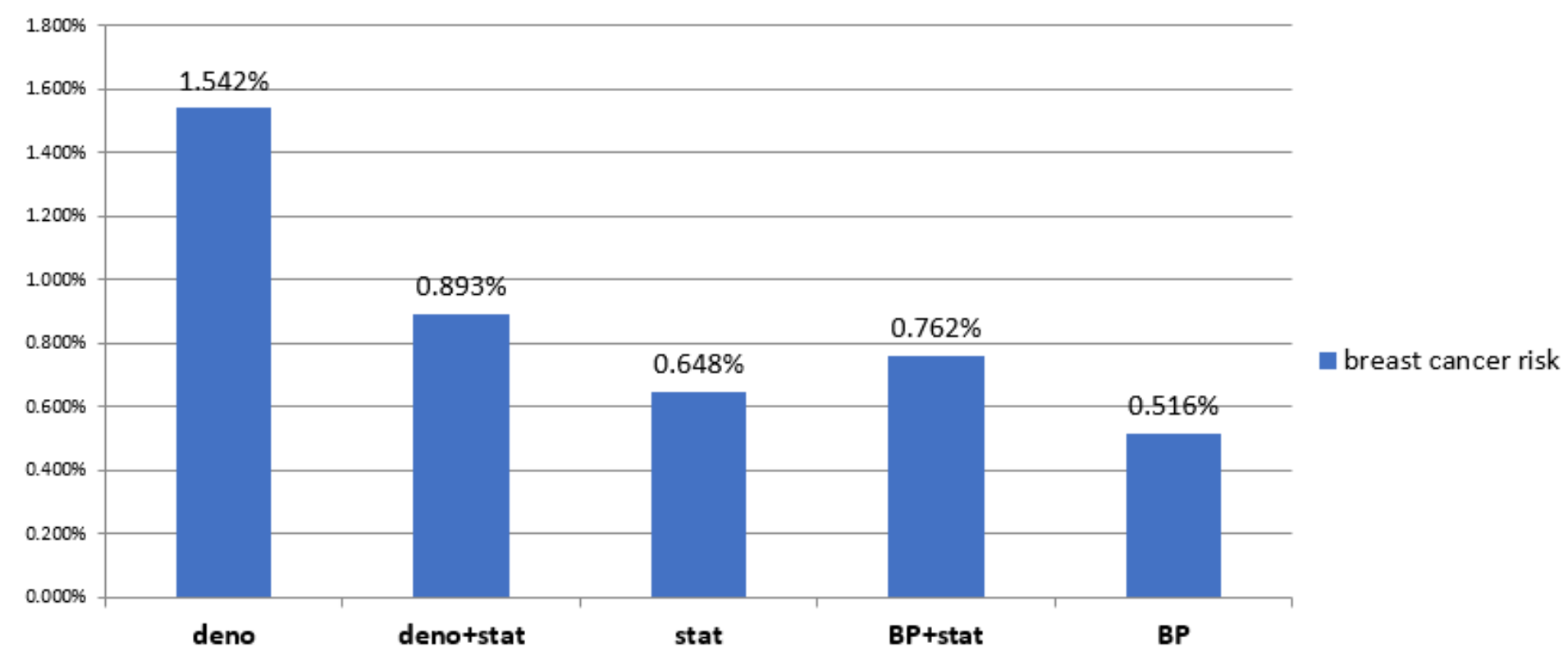

\section{Figure 3}

Breast cancer risk modification by concurrent statins use. Deno: denosumab, Stat: statins BP: bisphosphonates

\section{Supplementary Files}

This is a list of supplementary files associated with this preprint. Click to download.

- supplTable1.docx

- supplFigure2.pptx

- SuppFig1.jpg 